\title{
A Stress Management and Health Promotion Intervention for Parents of Children with Cerebral Palsy and Motor Disability at the Infant Department of the Greek Center for the Protection and Rehabilitation of the Disabled (ELEPAP). Quasi-Experimental Study
}

\author{
Efthymia Thanou ${ }^{1}$, Crysa Tsiou ${ }^{2}$, Christalena Kattami ${ }^{3}$, George P. Chrousos ${ }^{1,4}{ }^{*}$, \\ Christina Darviri ${ }^{* * \#}$ \\ ${ }^{1}$ Postgraduate Course Science of Stress and Health Promotion, School of Medicine, University of Athens, \\ Athens, Greece \\ ${ }^{2}$ Department of Nursing, Technological Education Institute, Athens, Greece \\ ${ }^{3}$ ELEPAP Rehabilitation for the Disabled, Athens, Greece \\ ${ }^{4}$ First Department of Pediatrics, Children's Hospital Aghia Sofia, School of Medicine, University of Athens, \\ Athens, Greece \\ Email: "cdarviri@yahoo.com
}

Received 17 February 2016; accepted 18 April 2016; published 21 April 2016

Copyright (C) 2016 by authors and Scientific Research Publishing Inc.

This work is licensed under the Creative Commons Attribution International License (CC BY).

http://creativecommons.org/licenses/by/4.0/

(c) (i) Open Access

\footnotetext{
Abstract

Studies show the correlation between children's physical disabilities and parental stress. The importance of the length of systemic therapy as well as stress management is emphasized in the literature. The present study aims to explore the outcome of a holistic stress management and health promotion intervention. This is a quasi-experimental study $(\mathrm{N}=60,1: 1$ allocation ratio). The study was conducted at ELEPAP, the Greek center for the protection and rehabilitation of the disabled. Self-administered scales were used to measure lifestyle variables, perceived stress, depression, and anxiety, locus of control, and spirituality. Stress management techniques were taught to the participants, who also attended lectures on health behaviors. Both quantitative and qualitative

${ }^{*}$ These authors contributed equally and share last authorship.

"Corresponding author.

How to cite this paper: Thanou, E., Tsiou, C., Kattami, C., Chrousos, G. P., \& Darviri, C. (2016). A Stress Management and Health Promotion Intervention for Parents of Children with Cerebral Palsy and Motor Disability at the Infant Department of the Greek Center for the Protection and Rehabilitation of the Disabled (ELEPAP). Quasi-Experimental Study. Psychology, 7, 557-564. http://dx.doi.org/10.4236/psych.2016.74057
} 
data were recorded. The objectives of the study were to reduce perceived stress levels, anxiety, and depressive symptoms, and improve the participants' quality of life, as well as to promote healthy dietary patterns. Regarding the stress levels and the depression symptoms, the objectives were achieved $(r=0.71$ and $r=0.78$ respectively). Lifestyle changes were also observed in nutrition $(r=0.92)$, exercise $(r=0.51)$, diet $(r=0.87)$, routine $(r=0.92)$, and social support $(r=0.92)$. Regarding spirituality, there was no significant difference. In conclusion, the present study demonstrates that intervention which combines stress management techniques with cognitive restructuring can reduce stress. It would be beneficial for children's parents to implement such interventions in a clinical setting.

\section{Keywords}

\section{Cerebral Palsy, Parents, Stress, Parental Stress, Anxiety, Depression, Relaxation}

\section{Introduction}

Cerebral palsy, also known as Little's disease, is a disorder of the Central Nervous System. It constitutes permanent, non-progressive anatomical damage of the motor centers of the brain, which manifests in impairments in both mobility and posture. The World Commission for cerebral palsy defines it as "permanent, but not irreversible impairment of muscle tone and movement, which is caused by a damage of the evolving nervous system before or during birth or in the first months of life" (Hodapp, 1998).

Cerebral palsy can also be defined as "a disorder of posture or movement which is persistent but not necessarily permanent, caused by non-progressive brain trauma during the growth period". It is worth noting that cerebral palsy is an umbrella term which includes a number of non-progressive, but often reversible motor dysfunction syndromes as secondary damage result or brain abnormalities arising in the early development stages (Houlihan et al, 2004; Bax et al., 2014; McCubbin \& McCubbin, 1987).

Cerebral palsy includes many diverse problems such as movement disorders, sensory disorders, learning disabilities, attention disorders, perception and language problems, behavioral disorders and mental retardation. Surveys have shown that about $60 \%$ of children with cerebral palsy have an intelligence quota (IQ) below 70 (Kuban \& Leviton, 1994).

Research findings have shown that children with physical disabilities are an important source of parental stress. This view is also reinforced by higher rates of divorce and depression, in both parents and siblings. Parents report that greater source of stress is the inability of the child to participate in motor activities or walking, rather than by parenting itself. The more disabilities manifested in the child the more stress the family experiences. Another factor that could cause stress is the demographic characteristics of the families. For example, single parent families, families in which parents are not married, families with low educational levels and families in which the mother is the head of family, experience higher and more intense stress levels. Moreover, the need for specialized services causes intense stress. Parents also experience stress because they usually spend large amounts of money in splints, physiotherapy sessions, orthopedics, or special shoes and wheelchairs (Abidin, 1995; Wills, 1993).

\section{Materials and Methods}

\subsection{Study Design}

This is a non randomized intervention with a total sample of $\mathrm{N}=60$ (intervention group $\mathrm{N}=30$, control group $\mathrm{N}$ $=30$ ). The study was conducted in the Greek company for the protection and rehabilitation of the disabled (ELEPAP), and approved by the Ethics Committee in September 2014. All individuals participating in the study gave informed, written consent and were individually informed about research aim and procedure.

\subsection{Data Collection and Randomization}

The inclusion criteria were having a child diagnosed with cerebral palsy aged 6 - 24 months, living in Athens, 
and good spoken and written Greek. Parents who did not meet the above criteria were excluded from this study. Parents with psychiatric comorbidity and parents who made use of other relaxation techniques, and parents on who were using psychotropic medications were excluded. Parents who came to ELEPAP were evaluated for the above criteria. Those who met the inclusion criteria were briefed on the study aims and procedures, and after consenting to join the study they chose whether they wanted to participate in the control or the intervention group. There was no randomization due to the nature of the population (parents who had trouble finding the personal time to participate in the study sessions) and the way the centre operates (it was requested by the director that no randomization is performed, to accommodate the parents' needs). Both groups were informed about the purpose of the program in the same way. They were also made aware that the research concerned stress and physical disabilities. In the intervention group, the role of the techniques for reducing stress, anxiety and depression levels was highlighted, whereas the control group was not given instructions for reducing stress. The participants then completed baseline measurements. The completed questionnaires were returned within three days. At the end of two months the diaries were delivered and the final measurements were completed.

\subsection{Intervention}

\section{Intervention Group}

The study comprised of an 8-week stress management and lifestyle change program including weekly sessions of stress management, dietary counseling, physical exercise and psychoeducation. In the initial session parents completed baseline measurements and attended a lecture on the stress system (April et al., 2012). They were informed about the role of exercise, locus of control, and daily routine. They were instructed to walk daily, with a goal of 10.000 steps per day and they were given a pedometer. Parents were encouraged to keep a structured daily routine with emphasis on meal times, awakening time, and bedtime .The second and third meeting included training in diaphragmatic breathing with the use of biofeedback equipment (BioTrace, Mind Media B.V.) and PMR. Parents were given sound files with recorded instructions for the techniques and were instructed to listen to the recording and exercise twice daily, in the morning and at night, at home. They were given a pen-and-paper relaxation diary to self-monitor their progress. The fourth meeting included training on cognitive restructuring and gratitude practice. Parents were given cognitive restructuring and gratitude pen-and-paper diaries to complete over the next week at home. In the Fifth meeting parents were also informed about diet plan reported in the literature. The sixth meeting included training in guided imaginary (Jacobson, 1938). They were given a pen-and-paper relaxation diary to self-monitor their progress. In the seventh meeting parents discussed their diaries with the researcher and were further encourage to adhere to the programme. At the last session, patients completed the final measurements (Jerath et al., 2006; Kaushik et al., 2005).

\subsection{Wait-List Control Group}

Participants in the control group at the beginning and at the end of the study completed the same questionnaires as those in the intervention group in order to assess the effect of stress on their health status. The difference with the intervention group is that those in the wait-list control group received the CD containing recorded instructions for the relaxation techniques and a written patient guide used at the intervention, at the end of the study, as an incentive to participate. The observation period of the wait-list control group also lasted two months.

\subsection{Measurements}

Sociodemographic variables, such as sex, age, educational level, number of children, marital status, and smoking status.

Perceived Stress Levels. Perceived Stress Scale, PSS 14, weighted in Greek was used (Paloutzian \& Ellison, 1982). The perceived stress scale (PSS) is a self-assessment scale with 14 items, which measures the degree to which situations in one's life are considered stressful on a 5-point Likert type scale. Good psychometric properties have been shown for the Greek population (Lyrakos et al., 2009; Cohen et al., 1983; Andreou et al., 2013).

Depression Anxiety Stress Scale-21. DASS-21 is a self administered questionnaire that has three subscales: depression, anxiety and stres.16 it is graded on a five-point Likert type scale. This scale has been validated in Greek (Lovibond \& Lovibond, 1995).

The Health Lifestyle and Personal Control Questionnaire (HLPCQ). This is a 26-item tool in which the res- 
pondent is asked to indicate the frequency of adopting 26 positively stated lifestyle habits using a Likert-type scale $(1=$ Never or rarely, $2=$ Sometimes, $3=$ Often and $4=$ Always). The introductory phrase is "How often...". There are 12 items concerning diet, 8 items referring to a daily time management, 2 items referring to organized physical exercise and 4 items referring to practices of social support and positive thinking (e.g., positive thoughts during difficulties and emptying the mind during bedtime) (Darviri et al., 2014).

Spiritual Well-Being Scale. The self-report scale consists of 20 questions graded on a Likert-type six point scale (Paloutzian \& Ellison, 1982).

\subsection{Sample Size}

The intervention was successfully completed without any dropouts. Out of the 80 parents who routinely came into the ELEPAP centre throughout the duration of the recruitment period, 70 parents met inclusion criteria and were informed about the study. 60 of them participated, while the others refused to participate due to limited spare time, and for health reasons. Blinded design could not be employed (Figure 1).

\subsection{Statistical Analysis}

Statistical analysis was done using the SPSS 21.0 program for Windows. Between-groups comparisons were performed using non parametrical tests (within and between analysis).

I considered $p$ value equal or smaller than 0.05 to be significant. To compare changes in outcomes between

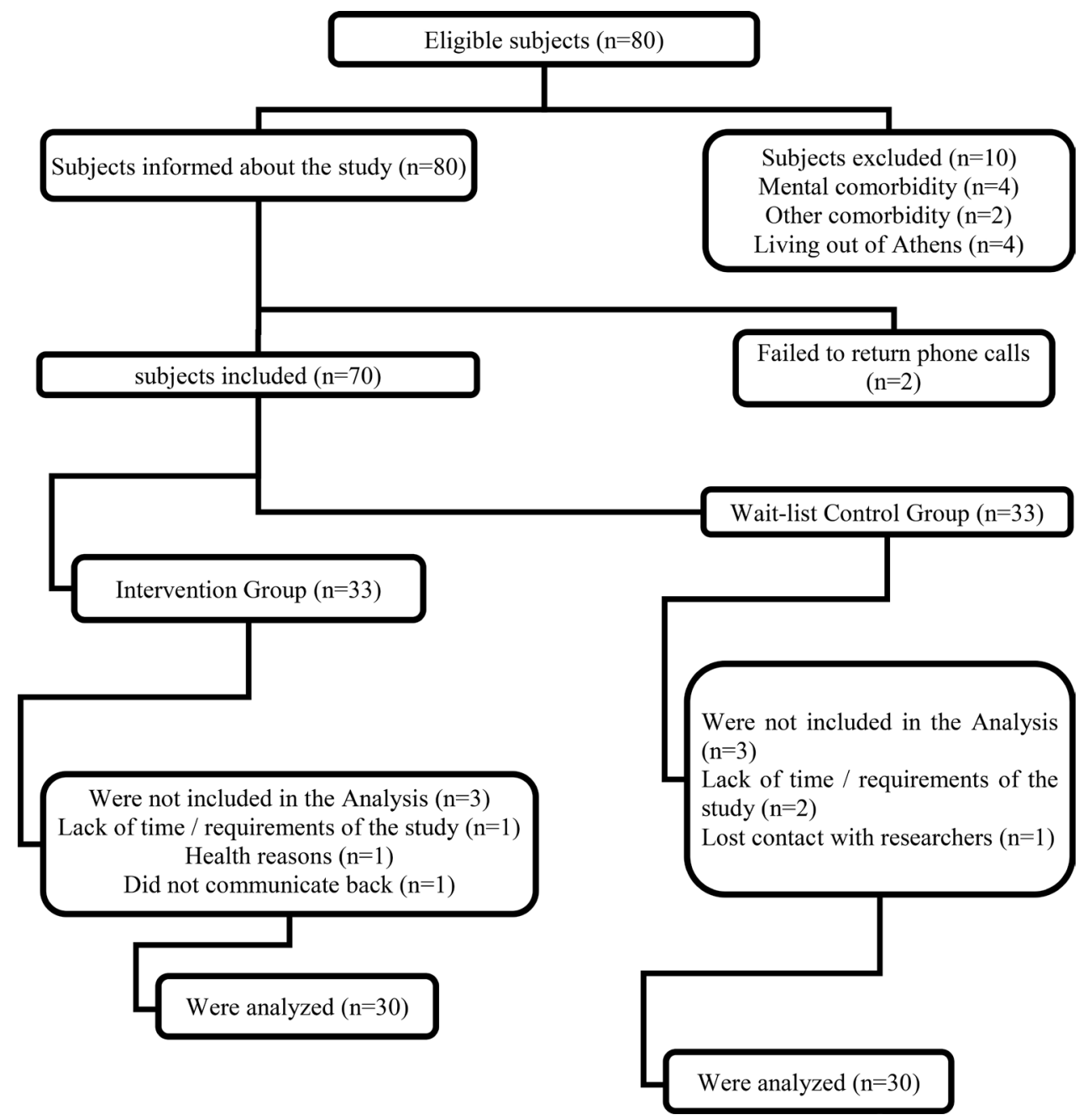

Figure 1. Participants flowchart. 
group, the difference between the final measurement and the baseline measurement was calculated for each scale, and Mann-Whitney U tests were run.

\section{Results}

\subsection{Sample Description and Baseline Measurements}

The average age for our sample was 36.1 years, $80 \%$ of participants were female. Groups were compared regarding smoking status, sex, age, number of children, educational level, and marital status. Statistically significant difference was observed for the number of children and marginally significant for the educational level of participants $(p<0.05$ and $p=0.052$ respectively). Baseline measurements between-groups were compared (Table 1). There was a statistically significant difference between the two groups with regard to DASS score (Anxiety subscale), HLPCQ (Total score, and subscales Dietary avoidance, Social support, Nutrition) and the Existential Subscale of SWB $(p>0.05)$.

\subsection{Outcomes}

As seen in Table 2, there is a statistically significant difference between the two groups in PSS-14 score ( $p<$ $0.001, r=0.79)$. Regarding the Anxiety and Depression subscales of DASS, there is also a statistically significant difference between the two groups ( $p<0.001, \mathrm{r}=0.78$ and $\mathrm{r}=0.71$ respectively).

Regarding the other measurements, statistically significant differences were found for the DASS Stress Subscale $(p<0.001, \mathrm{r}=0.87)$, the total score of HLPCQ $(p<0.001, \mathrm{r}=0.92)$, the dimension dietary choices of the HLPCQ $(p<0.001 \mathrm{r}=0.92)$, dietary avoidance of the HLPCQ $(p<0.001, \mathrm{r}=0.87)$, routine of the HLPCQ $(p<$ $0.001, \mathrm{r}=0.92)$, Exercise of the HLPCQ $(p<0.001, \mathrm{r}=0.51)$, and the existential dimension of the SWB $(p<$ $0.001, r=0.54)$. A large effect magnitude been observed for changes in the score of the Routine of HLPCQ, and the total score of HLPCQ. Regarding the dimension Spirituality of SWB, no statistically significant change was found $(p>0.05)$.

Table 1. Social and demographic characteristics of the participants.

\begin{tabular}{|c|c|c|c|}
\hline & Intervention Group $(\mathbf{N}=\mathbf{3 0})$ & Wait-list Control Group $(\mathbf{N}=\mathbf{3 0})$ & $p$ value \\
\hline Age (min-max) & $36.50(30,41)$ & $35.63(26.41)$ & 0.21 \\
\hline $\begin{array}{c}\text { Gender } \\
\text { Men }(\mathrm{N}, \%) \\
\text { Women }(\mathrm{N}, \%)\end{array}$ & $\begin{array}{c}4(13 \%) \\
26(87 \%)\end{array}$ & $\begin{array}{c}8(27 \%) \\
22(73 \%)\end{array}$ & 0.33 \\
\hline $\begin{array}{c}\text { Marital status } \\
\text { Married (N, \%) } \\
\text { Divorced (N, \%) }\end{array}$ & $\begin{array}{c}27(90 \%) \\
3(10 \%)\end{array}$ & $\begin{array}{c}30(100 \%) \\
0(0 \%)\end{array}$ & 0.24 \\
\hline $\begin{array}{c}\text { Educational attainment } \\
\text { Secondary education }(\mathrm{N}, \%) \\
\text { Post-secondary education }(\mathrm{N}, \%)\end{array}$ & $\begin{array}{c}5(17 \%) \\
25(83 \%)\end{array}$ & $\begin{array}{c}0(0 \%) \\
30(100 \%)\end{array}$ & 0.052 \\
\hline Smokers & $5(17 \%)$ & $11(37 \%)$ & 0.14 \\
\hline Number of Children (min-max) & $1.77(1,3)$ & $1.37(1,3)$ & $0.02 *$ \\
\hline \multicolumn{4}{|l|}{ Measurements } \\
\hline PSS (min, max) & $27.9000(43,16)$ & $26.6000(30,23)$ & 0.203 \\
\hline DASS Anxiety (min, max) & $3.0667(12,0)$ & $4.5000(8,1)$ & 0.039 \\
\hline DASS Stress (min, max) & $6.0333(15,0)$ & $7.4667(15,4)$ & 0.118 \\
\hline DASS Depression (min,max) & $4.1667(12,0)$ & $4.9667(13,0)$ & 0.439 \\
\hline HLPCQ Total score (min, $\max )$ & $59.5000(75,44)$ & $53.7667(58,46)$ & 0.000 \\
\hline HLPCQ nutrition (min, $\max )$ & $14.7667(7,22)$ & $12.3000(10,15)$ & 0.000 \\
\hline HLPCQ dietaryharmavoidance (min, $\max$ ) & $9.4333(12,6)$ & $10.2667(12,9)$ & 0.019 \\
\hline HLPCQ routine $(\min , \max )$ & $17.7667(28,8)$ & $16.9667(20,13)$ & 0.371 \\
\hline HLPCQ exercice (min, max) & $4.1667(7,2)$ & $3.5000(5,2)$ & 0.073 \\
\hline HLPCQ social support (min, $\max$ ) & $12.5333(17,7)$ & $10.7333(13,9)$ & 0.000 \\
\hline SWB spiritual (min, $\max )$ & $33.7000(52,20)$ & $35.7000(41,28)$ & 0.181 \\
\hline SWB existential (min, $\max$ ) & $30.2667(41,19)$ & $33.6333(44,19)$ & 0.045 \\
\hline
\end{tabular}


Table 2. Mann Whitney U for outcome change between groups (final measurement minus baseline measurement).

\begin{tabular}{|c|c|c|c|c|}
\hline & Intervention $(\mathbf{N}=\mathbf{3 0})$ & Control $(\mathbf{N}=\mathbf{3 0})$ & $p$ value & Effect size $r$ \\
\hline Mean $\triangle$ PSS (min, $\max )$ & $-9.37(-15.00,-5.00)$ & $-1.83(-8.00,1,00)$ & $<0.001$ & 0.79 \\
\hline$\Delta$ Mean DASS Depression (min, max) & $-2.67(-7.00,0.00)$ & $0.00(-1.00,1.00)$ & $<0.001$ & 0.78 \\
\hline$\Delta$ Mean DASS Anxiety (min, max) & $-1.80(-7.00,0.00)$ & $0.00(0.00,0.00)$ & $<0.001$ & 0.71 \\
\hline$\triangle$ Mean HLPCQ exercise (min, max) & $1.40(0.00,3.00)$ & $0.23(-2.00,3.00)$ & $<0.001$ & 0.51 \\
\hline$\triangle$ Mean HLPCQ nutrition (min, max) & $5.17(3.00,7.00)$ & $0.00(0.00,0.00)$ & $<0.001$ & 0.92 \\
\hline$\triangle$ Mean HLPCQ Diet (min, max) & $2.00(0.00,4.00)$ & $0.00(0.00,0.00)$ & $<0.001$ & 0.87 \\
\hline$\triangle$ Mean HLPCQ routine (min, $\max$ ) & $5.53(2.00,8.00)$ & $0.00(0.00,0.00)$ & $<0.001$ & 0.92 \\
\hline$\triangle$ Mean HLPCQ social support (min, $\max$ ) & $3.70(1.00,5.00)$ & $0.00(0,00,0.00)$ & $<0.001$ & 0.92 \\
\hline$\triangle$ Mean HLPCQ Total score (min, $\max$ ) & $16.97(7.00,23.00)$ & $0.00(0.00,0.00)$ & $<0.001$ & 0.92 \\
\hline$\Delta$ Mean SWB spiritual (min, max) & $0.30(-4.00,6.00)$ & $0.00(0.00,0.00)$ & 0.178 & 0.17 \\
\hline$\Delta$ Mean SWB existential (min, max) & $-1.30(-6.00,7.00)$ & $0.00(0.00,0.00)$ & $<0.001$ & 0.54 \\
\hline
\end{tabular}

\section{Discussion}

\subsection{Result Interpretation}

This interventional study evaluated the effect of an eight week behavioral change program with stress management as its main component, implemented on parents of children with cerebral palsy. The intervention included diaphragmatic breathing, progressive muscle relaxation, and guided imagery training, audiovisual material on exercise and nutrition, as well as training on cognitive restructuring and gratitude exercises.

The objectives of the study were to reduce stress and anxiety levels, to reduce depressive symptoms, to improve parents' quality of life, and to promote healthy dietary patterns. Regarding stress levels and depression symptoms, the objectives were achieved $(\mathrm{r}=0.71, \mathrm{r}=0.78)$. Through the intervention program, a change in lifestyle was observed in relation to social support and dietary patterns (HLPCQ diet $r=0$.92, HLPCQ exercise $r=$ 0.51 , HLPCQ Diet $r=0.87$, HLPCQ routine $r=0,92$, HLPCQ social support $r=0.92$ ). It is worth mentioning that, based on demographic data in Table 1. The intervention group as compared to the wait-list control group had originally reported better health related behaviours, thereby demonstrating an interest in self-care behaviours, a fact which may account for the great difference in final scores between the two groups.

\subsection{Comparison with Literature Findings}

The model of family adaptation, i.e. is the so-called model of "Dual AVGCH", aims to reduce parental stress. Therefore it was not possible to identify similar interventions in the existing literature, so as to compare against the intervention program implemented in this study. In addition, the intervention programs found in the literature do not refer to the parents themselves but to all caretakers of people with disabilities in general. Finally, many of the stress management programs in other studies are delivered to parents online. However, programs which applied stress management techniques, particularly mindfulness interventions to parents of disabled people, also had positive results on reducing stress and depression levels (Heaman, 1995; Ainbinder et al., 1998; Benn et al., 2012; Minor et al., 2006; Singer et al., 2007). A metanalysis of studies implemented on parents of children with various developmental disorders demonstrated that cognitive restructuring and behavioural interventions significantly reduce parental stress levels (Jones \& Passey, 2005; Hastings \& Beck, 2004).

\subsection{Generalization and Limitations of the Study}

Generalization of our results is limited to parents with similar socio-demographic background as the sample of this study (parents of children with cerebral palsy, aged in their mid-thirties, living in an urban environment, of post-secondary education).

There are several limitations in this study. Blinded study design could not be implemented and compliance with the program could not be verified in any way other than through the participants' self-report diary recordings. Furthermore, self-report measures combined with the lack of blinding, means that parents in the interven- 
tion group could have given favorable answers to the final measurements. Another drawback is that the demonstration of the techniques of the program was done gradually over a period of eight weeks, therefore, the time available for each technique to have an impact in outcomes was not the same. A key drawback in conducting the study was the lack of time. Sessions took place in a time limit of 20 minutes, because they were scheduled to coincide with the parents' regular physiotherapist and occupational therapist appointment, so as to enable parents to attend the intervention program. This made the implementation of the program harder for the researcher due to time pressure. Moreover, due to the fact that children were often ill during the week, it was difficult for parents to be consistent, which affected the group dynamic. Sometimes, the small space allocated for the program (an office also used by other staff members for various purposes), hindered proper implementation. In addition, since the meetings took place in the infant department of ELEPAP, there was often loud noise, disrupting the meetings.

\section{Conclusion and Suggestion}

In summary, the present study demonstrates that programs which combine stress management techniques with cognitive restructuring yield positive results in reducing stress levels in parents of children with cerebral palsy. These findings should be confirmed by future studies with larger sample sizes. It would be practical to conduct the program online, to accommodate parents who are employed, but also for parents residing outside the Athens area. It might be useful to reduce the number of sessions. This would enable to add other techniques in the intervention program. Furthermore, the allocation of a more private and quiet space for the implementation of the program would allow parents to be more relaxed and engage more. Finally, it would be interesting to implement this research in a clinical environment, where other health professionals could be involved.

\section{References}

Abidin, R. R. (1995). Parenting Stress Index-Manual. Charlottesville, VA: Pediatric Psychology Press.

Ainbinder, J. G. et al. (1998). A Qualitative Study of Parent to Parent Support for Parents of Children with Special Needs. Journal of Pediatric Psychology, 23, 99-109.

Andreou, E., Alexopoulos, E. C., Lionis, C., Varvogli, L., Gnardellis, C., Chrousos, G. P., \& Darviri, C. (2011). Perceived Stress Scale: Reliability and Validity Study in Greece. International Journal of Environmental Research and Public Health, 8, 3287-3298.

April, A. K., Dharani, B., \& Peters, K. (2012). Impact of Locus of Control Expectancy on Level of Well-Being. Review of European Studies, 4, 124-137.

Bax, M., Goldstein, M., Rosenbaum, P., Leviton, A., \& Paneth, N. (2005). Proposed Definition and Classification of Cerebral Palsy. Developmental Medicine and Child Neurology, 47, 571-576.

Benn, R., Akiva, T., Arel, S., \& Roeser, R. W. (2012). Mindfulness Training Effects for Parents and Educators of Children with Special Needs. Developmental Psychology, 48, 1476-1487. http://dx.doi.org/10.1037/a0027537

Cohen, S., Kamarck, T., \& Mermelstein, R. (1983). A Global Measure of Perceived Stress. Journal of Health and Social Behavior, 24, 385-396.

Darviri, C., Alexopoulos, E. C., Artemiadis, A. K., Tigani, X., Kraniotou, C., Darvyri, P., \& Chrousos, G. P. (2014). The Healthy Lifestyle and Personal Control Questionnaire (HLPCQ): A Novel Tool for Assessing Self-Empowerment through a Constellation of Daily Activities. BMC Public Health, 14, 995. http://dx.doi.org/10.1186/1471-2458-14-995

Hastings, R. P., \& Beck, A. (2004). Practitioner Review: Stress Intervention for Parents of Children with Intellectual Disabilities. Journal of Child Psychology and Psychiatry, 45, 1338-1349. http://dx.doi.org/10.1111/j.1469-7610.2004.00357.x

Heaman, D. J. (1995). Perceived Stressors and Coping Strategies of Parents Who Have Children with Developmental Disabilities: A Comparison of Mothers with Fathers. Journal of Pediatric Nursing, 10, 311-320.

Hodapp, M. R. (1998). Advancing Finding, Theories, and Methods Concerning Children with Disabilities. Athens: Cambridge University Press.

Houlihan, M., Donell, M., Conaway, M., \& Stevenson, R. D. (2004). Bodily Pain and Health-Related Quality of Life in Children with Cerebral Palsy. Developmental Medicine and Child Neurology, 46, 305-310. http://dx.doi.org/10.1111/j.1469-8749.2004.tb00490.x

Jacobson, E. (1938). Progressive Relaxation. Chicago: University of Chicago Press.

Jerath, R., Edry, J. W., Barnes, V. A., \& Jerath, V. (2006). Physiology of Long Pranayamic Breathing: Neural Respiratory Elements May Provide a Mechanism That Explains How Slow Deep Breathing Shifts the Autonomic Nervous System. 
Medical Hypotheses, 67, 566-571. http://dx.doi.org/10.1016/j.mehy.2006.02.042

Jones, J., \& Jennifer, P. (2005). Family Adaptation, Coping and Resources: Parents of Children with Developmental Disabilities and Behaviour Problems. Journal on Developmental Disabilities, 11, 31-46.

Kaushik, R., Kaushik, R. M., Mahajan, S. K., \& Rajesh, V. (2005). Biofeedback Assisted Diaphragmatic Breathing and Systematic Relaxation versus Propranolol in Long Term Prophylaxis of Migraine. Complementary Therapies in Medicine, 13, 165-174. http://dx.doi.org/10.1016/j.ctim.2005.04.004

Kuban, K. S. K., \& Leviton, A. (1994). Cerebral Palsy. The New England Journal of Medicine, 330, 1760.

Lovibond, S. H., \& Lovibond, P. F. (1995). Manual for the Depression Anxiety Stress Scales (2nd ed.). Sydney: Psychology Foundation.

Lyrakos, G. N., Arvaniti, C., Smyrnioti, M., \& Kostopanagiotou, G. (2011). P03-561-Translation and Validation Study of the Depression Anxiety Stress Scale in the Greek General Population and in a Psychiatric Patient's Sample. Greek Translation of the DASS European Psychiatry, 26, 1731.

McCubbin, M. A., \& McCubbin, H. I. (1987). Family Stress Theory and Assessment. In H. I. McCubbin, \& A. I. Thompson (Eds.), Family Assessment Inventories for Research and Practice (pp. 3-22). Madison, WI: University of WisconsinMadison.

Minor, H. G., Carlson, L. E., Mackenzie, M. J., Zernicke, K., \& Jones, L. (2006). Evaluation of a Mindfulness-Based Stress Reduction (MBSR) Program for Caregivers of Children with Chronic Conditions. Social Work in Health Care, 43, 91109. http://dx.doi.org/10.1300/J010v43n01 06

Paloutzian, R. F., \& Ellison, C. W. (1982). Subjective Measures of Spiritual Well-Being. Review of Religious Research, 25, 351-364.

Singer, G. H., Ethridge, B. L., \& Aldana, S. I. (2007). Primary and Secondary Effects of Parenting and Stress Management Interventions for Parents of Children with Developmental Disabilities: A Meta-Analysis. Mental Retardation and Developmental Disabilities Research Reviews, 13, 357-369. http://dx.doi.org/10.1002/mrdd.20175

Wills, K. E. (1993). Neuropsychological Functioning in Children with Spina Bifida and/or Hydrocephalus. Journal of Clinical Child Psychology, 22, 247-267. http://dx.doi.org/10.1207/s15374424jccp2202_11 